\title{
EUROPEAN IMMUNIZATION WEEK 2008 - TIME FOR REFLECTION
}

\author{
Peter Kreidl ${ }^{1}$, H Gomes $^{1}$, P. L. Lopalco ${ }^{1}$, K Hagmaier $^{1}$, L Pastore Celentano ${ }^{1}$, P Vasconcelos $^{1}$, C Yilmaz ${ }^{1}$ \\ 1. Vaccine Preventable Disease Programme Team, European Centre for Disease Prevention and Control (ECDC), Stockholm
}

This week's edition of Eurosurveillance is dedicated to European Immunization Week 2008, which will take place from 21 to 27 April. In 2005, the World Health Organization (WHO) organised the first European Immunization Week (http://www.euro.who.int/ vaccine/eiw/20050608_1) to increase vaccination coverage by raising awareness about the importance of immunisation, with a special focus on reaching vulnerable and hard-to-reach population groups. During the week, each participating country implements activities to inform and engage key target groups using the slogan "prevent-protect-immunise" and focuses on critical challenges regarding immunisation in their country.

In 2002, the WHO Regional Office for Europe developed a strategic plan for the elimination of measles and the prevention of congenital rubella, which was expanded in 2004 to reach the ambitious target to eliminate both diseases by 2010. 'Elimination' is defined as an incidence of measles less than one case per one million inhabitants per year and an incidence of congenital rubella of less than one case per 100,000 live births. One of the key indicators is to reach vaccination coverage with two doses of the measles, mumps and rubella (MMR) vaccine of at least $95 \%$ at national level and at least $90 \%$ in all districts.

Although considerable progress has been made since 2002, and vaccine coverage with MMR has increased dramatically, huge outbreaks of these diseases have nevertheless been reported in recent years and are still ongoing in western European countries. There are currently large outbreaks of measles with over 2,000 cases in Switzerland and over 180 cases in Austria, both of which may pose the risk of widespread distribution to other countries during the European football championship (EURO 2008), which will take place in both those countries in June [1].

Enhanced surveillance for measles has significantly improved by the implementation of non-invasive sampling techniques and genotyping. Genotyping provides a good tool for better understanding the epidemiological links of outbreaks and has demonstrated that many of the outbreaks in Europe, especially the recent outbreaks in western countries of the European Union (EU) are connected and often result in the exportation of cases to countries within and outside the EU.

Much effort has been expended, both by EU Member States and the $\mathrm{WHO}$, to strengthen immunisation policy, vaccine safety and quality, surveillance, response and communication. However, despite the development of a new strategic framework plan identifying key strategies, setting annual milestones, targeting hard-to-reach populations, there is still much more to be done if the target of elimination is to be reached.

In recent years, low MMR coverage in hard-to-reach populations has resulted in outbreaks among Roma and Sinti in Italy, and among travellers in the United Kingdom [2,3]. The latter was exported to Israel, resulting in a huge outbreak there, which has been ongoing for several months with around 1,000 cases $[4,5]$.

The decrease of vaccine coverage levels due to the upsurge of objectors against vaccination has been influenced by publications about a non-existent association between the MMR vaccine and autism and Morbus Crohn in The Lancet [6], and a general reluctance by many parents to put their children through vaccination schedules.

In many cases, outbreaks start in environments with a high proportion of susceptibles, for example in anthroposophic groups, which are known for their critical attitudes towards vaccination. These outbreaks may then be exported to the general population, as is currently the case in Salzburg, Austria, where the first cases emerged in an anthroposophic school with very low vaccination coverage.

In this issue, Muscat et al describe the measles situation in Europe with nearly 4,000 cases reported in 2007 and 19 deaths for the period 2005/6 in the EU/European Economic Area (EEA) and EU candidate countries [7]. But as underreporting and underdiagnosis are common, many more cases are likely to have occurred. Further rapid communications provide preliminary information on an ongoing outbreak in Austria (Schmid et al) and its international implications [8] and another current outbreak in Italy (Caputi et al) that highlights the need for improving measles control measures in a hospital setting [9]. An interesting short communication by Spiteri et al. reports on a recent cluster of rubella cases in Malta and results from a cross-sectional study in Northern Greece presented by Fylaktou et al. show lower than expected protection rates against both measles and mumps in certain age groups, such as infants and young adults, partly due to non-compliance with the second dose of MMR vaccination.

Finally, two articles look at mumps, albeit it from very different angles. Boxall et al report on a large outbreak in the Czech Republic, the cause of which has to be explored among several aspects of the 
current immunisation program: waning immunity, inadequate cold chain, other causes of vaccine failure [10]. And Kaic et al report an unusual horizontal transmission of the $L$-Zagreb mumps vaccine strain to parents following children's vaccination [11].

Mumps elimination is not yet a public health goal in Europe, but outbreaks of the disease can be seen as a sign of problems in the MMR immunisation strategy and every issue (including safety) related to mumps vaccination can be a threat to the measles and rubella elimination targets.

Elimination of measles and congenital rubella syndrome (CRS) will only happen with the concerted actions of all stakeholders. This should include the notification of every case, enhanced harmonised surveillance, contact tracing of exposed susceptibles, the communication of every outbreak in all EU Member States, and increasing vaccine coverage. Efforts must also be made to identify populations with low coverage and tailor strategies to address those communities. Different communication strategies must be identified to target these groups, and a strong commitment is needed to ensure that human and financial resources are also provided.

The revised International Health Regulations that came into force in June 2007 are an opportunity to strengthen the battle against measles, which is a highly contagious and dangerous disease. However, in view of the current situation, the elimination by 2010 looks like it may be very hard to achieve.

\section{References}

1. Richard JL, Masserey-Spicher M, Santibanez S, Mankertz A. Measles outbreak in Switzerland - an update relevant for the European football championship (EURO 2008). Euro Surveill 2008;13(8). Available from: http://www.eurosurveillance. org/edition/v13n08/080221_1.asp

2. Filia A, Curtale F, Kreidl P, Morosetti G, Nicoletti L, Perrelli F, Mantovani J, Campus D, Rossi G, Sanna M, Zanetti A, Magurano F, Fortuna C, Iannazzo S, Pompa M, Ciofi Degli Atti M. Cluster of measles cases in the Roma/Sint population, Italy, June-September 2006. Euro Surveill 2006;11(10):E061012.2. Available from: http://www.eurosurveillance.org/ew/2006/061012.asp\#2

3. Cohuet S, Morgan O, Bukasa A, Heathcock R, White J, Brown K, Ramsay M, Gross R. Outbreak of measles among Irish Travellers in England, March to May 2007. Euro Surveill 2007;12(6):E070614.1. Available from: http://www. eurosurveillance.org/ew/2007/070614.asp\#1

4. An outbreak of measles in an ultra-orthodox Jewish community in Jerusalem, Israel, 2007 - an in-depth report. Euro Surveill 2008:13(8). Available from: http://www.eurosurveillance.org/edition/v13n08/080221_3.asp

5. J Siegel-Itzkovich. A shot in the arm for the Health Ministry? Jerusalem Post (online edition). 12 April 2008. Available from: http://www.jpost.com/servlet/ Satellite?cid=1207649994396\&pagename=JPost\%2FJPArticle\%2FShowFull

6. Wakefield AJ et al. Ileal-lymphoid-nodular hyperplasia, non-specific colitis, and pervasive developmental disorder in children. Lancet. 1998;351(9103):637-41.

7. Muscat M, Bang H, Glismann S. Measles is still a cause for concern in Europe. Euro Surveill 2008;13(16). Available from: http://www.eurosurveillance.org/ edition/v13n16/080417 3.asp

8. Schmid D, Holzmann H, Abele S, Kasper S, König C, Meusburger $\mathrm{C}$ et al. An ongoing multi-state outbreak of measles linked to non-immune anthroposophic communities in Austria, Germany, and Norway, March/April 2008. Euro Surveill 2008;13(16). Available from: http://www.eurosurveillance. org/edition/v13n16/080417_4.asp

9. Caputi G. Tafuri S, Chironna M, Martinelli D, Sallustio A, Falco A et al. An outbreak of measles including nosocomial transmission in Apulia, south-east Italy, January-March 2008 - a preliminary report. Euro Surveill 2008;13(16). Available from: http://www.eurosurveillance.org/edition/v13n16/080417_5.asp

10. Boxall N, Kubínyiová M, Príkazský V, Beneš C, Cástková J. Increase in the number of mumps cases in the Czech Republic, 2005-2006. Euro Surveill 2008;13(16). Available from: http://www.eurosurveillance.org/edition/v13n16/080417_8.asp
11. Kaic B, Gjenero-Margan I, Aleraj B, Ljubin-Sternak S, Vilibic-Cavlek T, Kilvain S et al. Transmission of the L-Zagreb mumps vaccine virus, Croatia, 2005-2008. Euro Surveill 2008;13(16). Available from: http://www.eurosurveillance.org/ edition/v13n16/080417_9.asp

This article was published on 17 April 2008.

Citation style for this article: Kreidl P, Gomes H, Lopalco PL, Hagmaier K, Pastore Celentano L, Vasconcelos P, Yilmaz C. European Immunization Week 2008 - time for reflection. Euro Surveill. 2008;13(16):pii=18835. Available online: http://www. eurosurveillance.org/ViewArticle.aspx?ArticleId $=18835$ 